\title{
Determinants of Health Information Seeking Behavior among Persons with Cancer Aged 18 Years and Older in the United States
}

\author{
Chekesha M. Jordan, DO, MPH ${ }^{1 *}$, Stephanie Miles-Richardson, DVM, PhD ${ }^{1,2}$, Reinetta T. \\ Waldrop Dr.PH, MSHS, FACHE ${ }^{1,2}$, and Gemechu B. Gerbi, MSc, PhD ${ }^{1,2}$ \\ ${ }^{I}$ Master of Public Health Program, Morehouse School of Medicine, Atlanta, GA, USA \\ ${ }^{2}$ Department of Community Health and Preventive Medicine, Morehouse School of Medicine, 720 Westview \\ Drive SW, National Center for Primary Care (NCPC) Suite 346, Atlanta, GA 30310-1495, USA
}

*Corresponding Author: Chekesha M. Jordan, Department of Community Health and Preventive Medicine, 720 Westview Drive SW, National Center for Primary Care (NCPC) Suite 346, Atlanta, GA 30310-1495, USA. Email: ciordan@msm.edu

\begin{abstract}
Background: Cancer is the second most common cause of death in the US. Seeking information about cancer has been positively linked to cancer-related health outcomes. The objective of this study is to assess the factors associated with health information seeking behavior (HISB) among adults aged $\geq 18$ years with cancer in the United States.
\end{abstract}

Methods: Secondary data analysis was conducted using data from538 adults with cancer who participated in the 2014 Health Information National Trends Survey (HINTS).Descriptive statistics were used to compute frequencies. Bivariate and multivariable logistic regression analyses were conducted to assess determinants of HISB among adults with cancer in the United States. Analyses were conducted using SAS version 9.4.

Results: After adjusting for socio-demographic factors, factors that decreased the likelihood of persons with cancer seeking health information included being Non-Hispanic Asian (OR: 0.06; 95\% CI: 0.01-0.45); having less than a high school education (OR: 0.44; 95\% CI: 0.20-0.98); having some college education (OR: 0.27; 95\% CI: 0.09-0.77); and trusting cancer information from the Internet a little or not at all (OR: 0.43; 95\% CI: 0.23-0.82).

Conclusion: Our results suggest that being Non-Hispanic Asian, having less than a college graduate education, and trusting cancer information on the Internet a little or not at all decreased the likelihood of individuals with cancer seeking health information. This highlights the need for development of effective cancer communication interventions for this population.

Keywords: Health information seeking behavior, Cancer, Health Information National Trends Survey (HINTS), Communication

\section{INTRODUCTION}

Cancer is the second most common cause of death in the United States (US), subsequent only to heart disease $[1,2]$. Health informationseeking behavior (HISB) is the "intended behavior of an individual to satisfy perceived needs for health information" [3]. Different from information scanning, information seeking is intentionally, actively searching for health information on the internet, other forms of media or via conversation with a healthcare provider outside of the course of normal conversation. Information seeking has also been defined as "a conscious effort to acquire information in response to a need or gap in knowledge" [4]. Conversely, information scanning is passively or inadvertently encountering health information via exposure to the media or some other means such as routine conversation with another individual [5].

According to the Pew Internet \& American Life Project, $81 \%$ of adults in the US polled in 2012 reported using the Internet and $72 \%$ of those polled reported that they had searched for health information on the Internet [6]. Seeking information about cancer has been positively 
linked to cancer-related health outcomes [7]. Among those who seek information about cancer, it has been found that awareness of cancer, knowledge and beliefs related to cancer, and preventive behaviors such as screening are more frequent [7].

Differences in HISB exist by race or ethnicity, gender, level of education, and attitude towards or trust in a source of health information. HISB is more common among non-Hispanic whites, women, younger individuals, those with higher levels of education, persons with higher socioeconomic status and people with a chronic disease or cancer [3]. Especially for older adults, the most trusted source is frequently a health care provider, followed by the Internet [8].

Understanding the HISB of individuals with cancer is important to determine how various methods of communication are used to obtain health information and to create more effective health communication strategies across this population [9]. Having access to more information about the disease process and treatment options allows for better informed decision-making among cancer patients, permitting them to take a more active role in their health care [10].

Increased HISB has mostly been associated with positive cognitive, behavioral, physical, and affective outcomes [11]. Some of these include but are not limited to increased knowledge of the disease process, improvement upon ability to make informed decisions, increased perception of control, and an improved ability to cope [11]. Other positive outcomes include discussion of health information with health care providers, improved ability to take care of oneself as well as to stick to the treatment plan, and modifications in health behaviors [11]. Individuals who seek health information more frequently experience an increased quality of life and decreases in fear, anxiety, and distress [11]. Positive outcomes of seeking information include an increase in hope and feelings of empowerment among patients [11]. The objective of this study is to assess determinants of HISB among adults in the US.

\section{MeTHODS}

\subsection{Data Source}

Data were analyzed from the 2014 Health Information National Trends Survey (HINTS), Cycle 4 to determine factors associated with HISB among persons with cancer aged 18 and older in the US. HINTS is a biennial, crosssectional survey of a nationally representative sample of non-institutionalized civilian American adults age 18 and older that is used to measure the influence of the health information environment. HINTS gauges how individuals in the US obtain and utilize health information, how information technology is used to manage health and health information, and to track this population's involvement in healthy behaviors. Additionally, several items specifically focus on cancer prevention and control. This study relied on secondary data from HINTS 2014, Cycle 4 which was the first iteration of HINTS to include questions regarding trust in sources of health information.

\section{MEASURES}

All measures in this study were based on selfreported data obtained from the 2014 HINTS, Cycle 4.

\subsection{Dependent Variable}

Self-reported HISB was determined if the participants answered "yes" to the question: "Have you ever looked for information about health or medical topics from any source?" Responses included "yes", "no", "unknown", or "refused". Records with "unknown" or refused" responses or missing data were excluded from the analysis to minimize underestimation.

\subsection{Covariates and Independent variables}

Participants' gender, race/ethnicity, age, level of education, level of income, access to health insurance, and trust in sources of health information were assessed from the 2014 HINTS, Cycle 4.

\subsection{Statistical Analyses}

Descriptive statistics were used to compute frequencies. A bivariate analysis, using the chisquare test statistic $(\chi 2)$, was conducted to assess factors independently associated with selfreported HISB among persons with cancers aged $\geq 18$ years in the US.A multivariable logistic regression analysis was used to estimate the adjusted odds ratios (AORs), the 95\% confidence intervals (CIs) for odds ratios, and $p$ values for each of the independent variables. Variables that were significant at the $\leq 0.05$ level in the bivariate analyses were entered into the multivariable logistic regression model. All analyses were conducted using SAS version 9.4 [12]. A value of $p \leq 0.05$ was considered statistically significant. 
Determinants of Health Information Seeking Behavior among Persons with Cancer Aged 18 Years and Older in the United States

\section{Results}

The sociodemographic characteristics of the study population, all of whom responded to the HISB question, are summarized in Table 1. Of the 538 participants who answered "yes" to the question: "Have you ever looked for information about health or medical topics from any source?", $453(84.2 \%)$ reported seeking HISB, while 85 (15.8\%) did not report seeking HISB. Of the 453 who reported seeking HISB, the majority were female $(60.1 \%)$, NonHispanic Whites $(74.7 \%)$, aged $\geq 45$ years $(92.5 \%)$, had a high school education or less (43.7\%), had an annual household income of less than $\$ 50,000(52.9 \%)$, and had health insurance $(94.3 \%)$.Furthermore, the large proportion of the respondents who trusted cancer information from a doctor, internet, and family a lot or some of the time were96.6\%, $73.1 \%$, and $52 \%$, respectively (Table 1 ).

Table 1. Number* and percentage for self-reported health information seeking in persons with cancer by select characteristics $(N=538): 2014$ HINTS, United States

\begin{tabular}{|c|c|c|c|c|}
\hline \multirow[t]{3}{*}{ Select Characteristics } & \multicolumn{3}{|c|}{$\begin{array}{l}\text { Have you ever looked for information about health or } \\
\text { medical topics from any source? }\end{array}$} & \multirow[b]{2}{*}{ p-value } \\
\hline & Total & No & Yes & \\
\hline & n (\%) & n (\%) & $\mathrm{n}(\%)$ & \\
\hline Overall & $538(100)$ & $85(15.8)$ & $453(84.2)$ & \\
\hline Gender & & & & 0.35 \\
\hline Male & $197(40.8)$ & $33(45.8)$ & $164(39.9)$ & \\
\hline Female & $286(59.2)$ & $39(54.2)$ & $247(60.1)$ & \\
\hline Total & $483(100)$ & $72(100)$ & $411(100)$ & \\
\hline Race/Ethnicity & & & & 0.001 \\
\hline Non-Hispanic White & $334(73.3)$ & $42(64.6)$ & $292(74.7)$ & \\
\hline $\begin{array}{l}\text { Non-Hispanic Black or } \\
\text { African American }\end{array}$ & $50(11.0)$ & $5(7.7)$ & $45(11.5)$ & \\
\hline Hispanic & $50(11.0)$ & $14(21.5)$ & $36(9.2)$ & \\
\hline Non-Hispanic Asian & $5(1.0)$ & $3(4.6)$ & $2(0.5)$ & \\
\hline Non-Hispanic Other & $17(3.7)$ & $1(1.6)$ & $16(4.1)$ & \\
\hline Total & $456(100)$ & $65(100)$ & $391(100)$ & \\
\hline Age Group & & & & 0.91 \\
\hline $18-34$ & $9(1.8)$ & $1(1.3)$ & $8(1.9)$ & \\
\hline $35-39$ & $9(1.8)$ & $1(1.3)$ & $8(1.9)$ & \\
\hline $40-44$ & $18(3.5)$ & $2(2.5)$ & $16(3.7)$ & \\
\hline 45 and above & $473(92.9)$ & $74(94.9)$ & $399(92.5)$ & \\
\hline Total & $509(100)$ & $78(100)$ & $431(100)$ & \\
\hline Level of Education & & & & $<0.0001$ \\
\hline Less than high school & $206(40.3)$ & $17(21.8)$ & $189(43.7)$ & \\
\hline High school graduate & $163(31.9)$ & $24(30.8)$ & $139(32.1)$ & \\
\hline Some college & $94(18.4)$ & $22(28.2)$ & $72(16.6)$ & \\
\hline $\begin{array}{l}\text { College graduate or } \\
\text { more }\end{array}$ & $48(9.4)$ & $15(19.2)$ & $33(7.6)$ & \\
\hline Total & $511(100)$ & $78(100)$ & $433(100)$ & \\
\hline Level of Income & & & & 0.02 \\
\hline Less than $\$ 50,000$ & $262(55.7)$ & $50(72.5)$ & $212(52.9)$ & \\
\hline$\$ 50,000$ to $\$ 74,999$ & $72(15.3)$ & $8(11.6)$ & $64(16.0)$ & \\
\hline$\$ 75,000$ to $\$ 99,999$ & $56(12.0)$ & $6(8.7)$ & $50(12.4)$ & \\
\hline$\$ 100,000$ or more & $80(17.0)$ & $5(7.2)$ & $75(18.7)$ & \\
\hline Total & $470(100)$ & $69(100)$ & $401(100)$ & \\
\hline Health Insurance & & & & 0.17 \\
\hline Yes & $492(93.7)$ & $75(90.4)$ & $417(94.3)$ & \\
\hline $\mathrm{No}$ & $33(6.3)$ & $8(9.6)$ & $25(5.7)$ & \\
\hline
\end{tabular}


Determinants of Health Information Seeking Behavior among Persons with Cancer Aged 18 Years and Older in the United States

\begin{tabular}{|c|c|c|c|c|}
\hline Total & $525(100)$ & $83(100)$ & $442(100)$ & \\
\hline $\begin{array}{l}\text { How much do you trust cancer } \\
\text { information from a doctor? }\end{array}$ & & & & 0.001 \\
\hline A lot/Some & $503(95.3)$ & $73(88.0)$ & $430(96.6)$ & \\
\hline A little/Not at all & $25(4.7)$ & $10(12.0)$ & $15(3.4)$ & \\
\hline Total & $528(100)$ & $83(100)$ & $445(100)$ & \\
\hline $\begin{array}{l}\text { How much do you trust cancer } \\
\text { information from the internet? }\end{array}$ & & & & $<0.0001$ \\
\hline A lot/Some & $334(69.6)$ & $33(48.5)$ & $301(73.1)$ & \\
\hline A little/Not at all & $146(30.4)$ & $35(51.5)$ & $111(26.9)$ & \\
\hline Total & $480(100)$ & $68(100)$ & $412(100)$ & \\
\hline $\begin{array}{l}\text { How much do you trust cancer } \\
\text { information from family? }\end{array}$ & & & & 0.52 \\
\hline A lot/Some & $251(51.4)$ & $33(47.8)$ & $218(52.0)$ & \\
\hline A little/Not at all & $237(48.6)$ & $36(52.2)$ & $201(48.0)$ & \\
\hline Total & $488(100)$ & $69(100)$ & $419(100)$ & \\
\hline
\end{tabular}

*Frequency may vary due to missing values

Table 2 shows the results of multivariable logistic regression adjusted for sociodemographic characteristics (gender, race or ethnicity, age, education, income), level of trust in cancer information from a doctor, internet, and family regressed on self-reported HISB among persons with cancer. Factors that decreased the likelihood of HISB included being Non-Hispanic Asian (AOR=0.06; 95\% CI=0.01, 0.45 ); having less than a high school education (AOR $=0.44 ; 95 \% \mathrm{CI}=0.20,0.98$ ); having some college education $(\mathrm{AOR}=0.27 ; 95 \% \mathrm{CI}=0.09$, 0.77 ); and trusting cancer information from the Internet a little or not at all (AOR $=0.43$; 95\% $\mathrm{CI}=0.23,0.82$ ). Individuals with some college education were $73 \%$ less likely to seek cancer information and trusting cancer from the Internet a little or not at all was associated with a 57\% decreased likelihood of seeking cancer information from the Internet.

\section{Discussion}

Seeking information about cancer has been positively linked to cancer-related health outcomes [7]. Individuals who seek information about cancer were more likely to have cancerrelated awareness, knowledge, beliefs, preventive behaviors, and screening adherence [7]. In the presentstudy, Non-Hispanic Asians were $94 \%$ less likely to seek cancer information. The same was reported previously [13]. Four possible explanations can be offered for a decreased likelihood of health information seeking among Non-Hispanic Asians. First, Non-Hispanic Asians tend towards having a lower sense of self-risk for cancer when compared to Whites [13]. Second, Non-Hispanic Asians do prefer print materials as a primary source of health information [13]. Third, NonHispanic Asians could experience a language barrier especially among recent immigrants and first-generation immigrants. The final possible explanation could be the presumed propensity among Asians to favor Eastern medicine and philosophies in lieu of more westernized models.

Consistent with previous studies [3, 14], individuals with less than a high school education were $56 \%$ less likely to seek cancer information. One possible explanation could be due to decreased health literacy levels. A study which investigated differences in HISB between individuals with and without a high school diploma, found that individuals without a high school diploma reported lower usage of textbased sources such as the Internet or books but higher usage of oral sources of health information such as radio and television [15]. Almost equal rates of use of health care providers as a source of information existed between groups with and without a high school diploma [15].However, the Internet proved to be a moderating factor showing that individuals without a high school diploma, who normally would have worse health status, could improve their health status with Internet use and improving their "health-related digital literacy skills" even beyond the health status of those with high school diplomas [15]. 
Determinants of Health Information Seeking Behavior among Persons with Cancer Aged 18 Years and Older in the United States

Table 2. Associations of persons with cancer who sought health related information by select characteristics, according to the multivariable logistic regression final model: 2014 HINTS, United States (N=453)

\begin{tabular}{|c|c|c|}
\hline \multirow{2}{*}{$\begin{array}{l}\text { Select Characteristics } \\
\text { Race/Ethnicity } \\
\end{array}$} & \multicolumn{2}{|c|}{$\begin{array}{c}\text { Adjusted OR(95\% CI)for } \\
\text { Persons with Cancer Who Sought Health Information }\end{array}$} \\
\hline & OR & $95 \% \mathrm{CI}$ \\
\hline Non-Hispanic White & Ref & \\
\hline Non-Hispanic Black or African American & 1.05 & $0.37-2.98$ \\
\hline Hispanic & 0.76 & $0.29-1.97$ \\
\hline Non-Hispanic Asian & 0.06 & $0.01-0.45$ \\
\hline Non-Hispanic Other & 2.04 & $0.25-16.69$ \\
\hline \multicolumn{3}{|l|}{ Level of Education } \\
\hline Less than high school & 0.44 & $0.20-0.98$ \\
\hline High school graduate & 0.51 & $0.19-1.35$ \\
\hline Some college & 0.27 & $0.09-0.77$ \\
\hline College graduate or more & Ref & \\
\hline \multicolumn{3}{|l|}{ Income } \\
\hline Less than $\$ 50,000$ & 0.57 & $0.19-1.75$ \\
\hline$\$ 50,000$ to $\$ 75,000$ & 1.08 & $0.27-4.18$ \\
\hline$\$ 75,000$ to $\$ 99,999$ & 0.56 & $0.15-2.10$ \\
\hline$\$ 100,000$ or more & Ref & \\
\hline \multicolumn{3}{|l|}{$\begin{array}{l}\text { How much do you trust cancer information } \\
\text { from a doctor? }\end{array}$} \\
\hline A lot/Some & Ref & \\
\hline A little/Not at all & 0.37 & $0.09-1.54$ \\
\hline \multicolumn{3}{|l|}{$\begin{array}{l}\text { How much do you trust cancer information } \\
\text { from the internet? }\end{array}$} \\
\hline A lot/Some & Ref & \\
\hline A little/Not at all & 0.43 & $0.23-0.82$ \\
\hline
\end{tabular}

Consistent with the literature, trusting cancer information from the Internet a little or not at all was also associated with a decreased likelihood of an individual with cancer seeking health information. The sheer volume of information available on the Internet can be intimidating as well as unreliable, making it a less trustworthy source. Regardless of one's experience using the Internet, consumer trust in online sources of health information is mediated by quality of message and the credibility of a website [16].

Interestingly, Miller and Bell (2012) posit that trust in sources of Internet health information becomes stronger across adulthood [17]. They also cite that there is a larger digital divide among older adopters and non adopters versus younger adopters and non adopters in that older adults tend to have a particularly pronounced distrust of Internet information in comparison to their younger counterparts, even when controlling for quality of healthcare, perceived general health, and age-related decline in Internet use for other common activities such as e-mail [17]. A possible reason for this phenomenon, as stated by Miller and Bell (2012), includes some individuals requiring more time to get comfortable using the Internet. They also pointed to the fact that health care providers remain the most popular source of health information, particularly among older adults [17]. One way of mediating trust of the Internet is for health care providers to recommend trusted sites to patients. Another way is for providers to print additional information from the Internet during visits for patients to read later.

\subsection{Study Strengths And Limitations}

One strength of this study was that the data used were from a nationally representative sample, so it could possibly be generalized to the US population. Another strength is that this study relied on secondary data from HINTS 2014, Cycle 4 which was the first iteration of HINTS to include questions regarding trust in various sources of health information.

One limitation of this study includes the use of cross-sectional data in this analysis, indicating that no inference can be made regarding causality. Additionally, the data in this study were self-reported and can be subject to recall bias. Another limitation includes the fact that many questions were left unanswered, thus 
limiting interpretation due to non response bias. An additional limitation is that HINTS, like many other surveys sent via mail, usually has a low response rate, thus decreasing its power of generalizability. HINTS 2014, Cycle 4 had a response rate of 34.44 percent, slightly lower than the previous three cycles, which ranged from 35.2 to forty percent [18].

\section{CONCLUSiON}

Factors that decreased the likelihood of persons with cancer seeking health information included being Non-Hispanic Asian, having less than a high school education, having some college education, and trusting cancer information from the Internet a little or not at all. These findings underscore the need for focused efforts to increase HISB among persons with cancer and bolster communication with at-risk groups.

\section{ACKNOWLEDGEMENTS}

We would like to acknowledge the Morehouse School of Medicine Master of Public Health Program.

\section{ETHICAL APPROVAL}

This study received exempt institutional review board (IRB) approval from the Morehouse School of Medicine IRB.

\section{REFERENCES}

[1] Huerta, T. R., Walker, D. M., Johnson, T., \& Ford, E. W., (2016). A time series analysis of cancer-related information seeking: Hints from the Health Information National Trends Survey (HINTS) 2003-2014. Journal of Health Commu nication, 21(9), 1031-1038.doi:10.1080/1081 0730.2016.1204381

[2] Heron M. (2018). Deaths: Leading causes for 2016. National Vital Statistics Reports, 67(6). Hyattsville, MD: National Center for Health Statistics.

[3] Jung, M. (2014). Determinants of health information-seeking behavior: Implications for post-treatment cancer patients. Asian Pacific Journal of Cancer Prevention, 15(16), 64996504. doi:10.7314/apjcp. 2014.15.16.6499

[4] Case, D, \& Given, L. (2016). Looking for information: A survey of research on information seeking, needs, and behavior: 4th Edition (Studies in Information) [Kindle version]. Retrieved from Amazon.com

[5] Waters, E. A., Wheeler, C., \& Hamilton, J. G. (2016). How are information seeking, scanning, and processing related to beliefs about the roles of genetics and behavior in cancer causation? Journal of Health Communication, 21(Sup2), 615. doi:10.1080/10810730.2016.1193917

[6] Fox, S. \& Duggan, M. (2013, January 15). Information triage. Pew Internet \& American Life Project. Retrieved from http://pewinte rnet.org/Reports/2013/Health-online.aspx

[7] Wigfall, L. T., \& Friedman, D. B. (2016). Cancer information seeking and cancer-related health outcomes: A scoping review of the Health Information National Trends Survey literature. Journal of Health Communication, 21(9),989-1005.doi:10.1080/10810730.2016. 1184358

[8] Powe, B. D. (2015). Health information seeking among rural African Americans, Caucasians, and Hispanics: Is it built, did they come? Nurs Clin North Am, 50(3), 531-543. doi:10.1016/ j.cnur.2015.05.007

[9] Rice, D. P., \& Fineman, N. (2004). Economic implications of increased longevity in the United States. Annu Rev Public Health, 25, 457-473.

doi:10.1146/annurev.publhealth.25.101802.123 054

[10] Maliski, S. L., Connor, S., Fink, A., \& Litwin, M. S. (2006). Information desired and acquired by men with prostate cancer: Data from ethnic focus groups. Health Educ Behav, 33(3), 393409. doi:10.1177/1090198105276223

[11] Lambert, S. D., \& Loiselle, C. G. (2007). Health information seeking behavior. Qual Health Res, 17(8), 1006-1019. doi:10.1177/ 104 9732307305199 SAS Institute, Cary, and NC.

[12] Nguyen, G. T., \& Bellamy, S. L. (2006). Cancer information seeking preferences and experiences: disparities between Asian Americans and Whites in the Health Information National Trends Survey (HINTS). J Health Commun, 11 Suppl 1, 173-180. doi:10. 1080/10810730600639620

[13] Lee, C. J., Ramirez, A. S., Lewis, N., Gray, S. W., \&Hornik, R. C. (2012). Looking beyond the Internet: examining socioeconomic inequalities in cancer information seeking among cancer patients. Health Commun, 27(8), 806-817. doi:10.1080/10410236.2011.647621

[14] Feinberg, I., Frijters, J., Johnson-Lawrence, V., Greenberg, D., Nightingale, E., \& Moodie, C. (2016). Examining associations between health information seeking behavior and adult education status in the US: An analysis of the 2012 PIAAC data. PLoS One, 11(2), e0148751. doi:10.1371/journal.pone.0148751

[15] Ye, Y. (2011). Correlates of consumer trust in online health information: findings from the 
health information national trends survey. $\mathrm{J}$ Health Commun, 16(1), 34-49. doi:10.1080/ 10810730.2010 .529491

[16] Miller, L. M., \& Bell, R. A. (2012). Online health information seeking: The influence of age, information trustworthiness, and search challenges. J Aging Health, 24(3), 525-541. doi:10.1177/0898264311428167

[17] Maitland, A., Lin, A., Cantor, D., et al. (2017). A nonresponse bias analysis of the Health Information National Trends Survey (HINTS). J Health Commun, 22(7), 545-553.doi:10.1080/ 10810730.2017.1324539

Citation: Chekesha M. Jordan, Stephanie Miles-Richardson, Reinetta T. WaldropDr.PH, Gemechu B. Gerbi. Determinants of Health Information Seeking Behavior among Persons with Cancer Aged 18 Years and Older in the United States. ARC Journal of Public Health and Community Medicine. 2020; 5(1):8-14. DOI: dx.doi. org /10.20431/2456-0596.0501003.

Copyright: (c) 2020 Authors. This is an open-access article distributed under the terms of the Creative Commons Attribution License, which permits unrestricted use, distribution, and reproduction in any medium, provided the original author and source are credited. 